\title{
Agricultural practices and age of chronic myeloid leukemia diagnosis in India
}

\author{
Andrew W. Hill ${ }^{\mathrm{a}, *}$, Melissa J. Perry ${ }^{\mathrm{b}}$, Paul H. Levine ${ }^{\mathrm{a}, \mathrm{c}}$ \\ ${ }^{a}$ The George Washington University School of Public Health and Health Services, Department of Epidemiology and Biostatistics, 950 New Hampshire Avenue, NW, 7th \\ Floor, Washington, DC, 20052, USA \\ ${ }^{\mathbf{b}}$ The George Washington University School of Public Health and Health Services, Department of Epidemiology and Biostatistics, 950 New Hampshire Avenue, NW, 4th \\ Floor, Washington, DC, 20052, USA \\ ${ }^{\mathrm{c}}$ The University of Nebraska Medical Center College of Public Health, Department of Epidemiology, 984395 Nebraska Medical Center, Omaha, NE, 68198-4395, USA
}

\section{A R T I C L E I N F O}

\section{Keywords:}

Cancer

Chronic myeloid leukemia

CML

Age of diagnosis

Agricultural exposure

\begin{abstract}
A B S T R A C T
Background/objective: Within India, chronic myeloid leukemia (CML) mean age at diagnosis is 38 years. This study investigated agricultural practices and patterns corresponding to regional variations in CML epidemiology in India.

Methods: Multivariable linear regression and a Cox proportional hazards assessment were used to determine associations between age of CML diagnosis and crop-specific regions.

Results: Patients in the agriculture/fishing occupation sector from high rice-production areas developed CML earlier (2.71 years) than those living in areas with lower levels of rice production ( $\mathrm{p}$-value $=.01$ ).

Conclusions: These data show a geographic relationship between crops grown and mean age of CML diagnosis. Whether crop type is a reflection of differences in specific occupational chemical uses or dietary practices, and how each of these factors relates to CML risk requires investigation at the individual level.
\end{abstract}

\section{Introduction}

Chronic myeloid leukemia (CML) is a rare hematological cancer that starts in the blood-forming cells of the bone marrow. Information regarding the epidemiology of CML in low- and middle-income countries is still emerging, but some recent studies have begun to fill this this gap. ${ }^{1}$ The Glivec International Patient Assistance Program (GIPAP), established through a partnership between Novartis and The MAX Foundation, provides treatment and monitoring to eligible CML patients in 80 countries worldwide. ${ }^{2,3}$ Using GIPAP data, we recently reported considerable variation in CML age at diagnosis in different populations worldwide, ${ }^{2}$ and in India, the average CML age at diagnosis is approximately 38 years; ${ }^{2}$ for reference, the average CML age of onset in the U.S. is approximately 64 years. ${ }^{4}$ The large number of GIPAP patients in India $(14,167)$ allowed a more detailed analysis of different factors and revealed that patients who were self/employed and worked in agriculture/fishing were more likely to be diagnosed at a younger age than patients working in the government. ${ }^{5}$ Additionally, within India, CML age at diagnosis varies geographically. ${ }^{1}$ Agriculture practices in India differ according to crops, and crops are not evenly geographically distributed (Fig. 1). ${ }^{6}$

Agricultural communities in India have potentially high exposures to pesticides, herbicides, and insecticides. ${ }^{7-9}$ Exposures to agricultural chemicals have been linked to health problems. In three studies conducted in the U.S., Blair et al. investigated the association of agricultural practices with leukemia cell types, ${ }^{10-12}$ and in two death certificate studies in Nebraska and Wisconsin they identified an elevated risk of leukemia among farmers. ${ }^{10,11}$ The third study categorized the counties of Nebraska according to agricultural practice (dairy, corn, etc.) and assessed odds ratios for different leukemia cell types by predominant agricultural practice of the counties. ${ }^{12}$ The authors concluded that focus on specific cell types is needed to better evaluate the role of farm practices in the origin of leukemia. Given the earlier age of onset of CML in patients in India employed in agriculture/fishing found previously, ${ }^{5}$ this study was undertaken to explore a possible correlation between specific agricultural patterns and regional variations in CML age at diagnosis in India.

\section{Materials and Methods}

\subsection{Population and agricultural data}

State area (in $\mathrm{km}^{2}$ ) and land use statistics from each state within India were obtained from the online database of the Agriculture Census

\footnotetext{
* Corresponding author. Present Address: 545 1/2 W. Arlington Place, Apartment 306, Chicago, IL, 60614, USA.

E-mail addresses: andrew.hill@PAREXEL.com (A.W. Hill), mperry@gwu.edu (M.J. Perry), paulhlevine@earthlink.net, Paul.Levine@unmc.med (P.H. Levine).
} 


\section{STATE HIGH / LOW CLUSTERS BY SPECICIF CROP ACCORDING TO PERCENTAGE OF LAND USED}
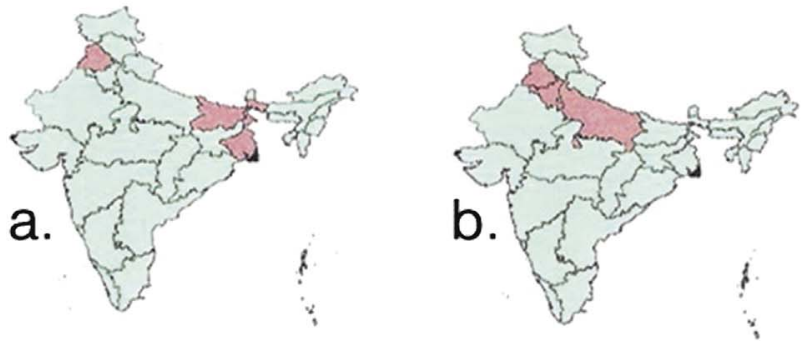

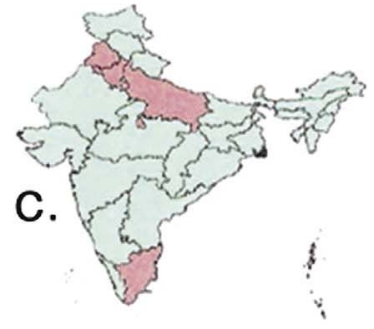

Fig 1. State High/Low Clusters by Specific Crop According to Percentage of Land Used.

"Data from online database of the Agriculture Census in India conducted by the Department of Agriculture and Co-operation.

The top $10 \%$ of states per each crop's land use (determined by univariate analysis using the $90 \%$ quantile cutoff) was considered to be "high" while the rest of states were considered "low."

High
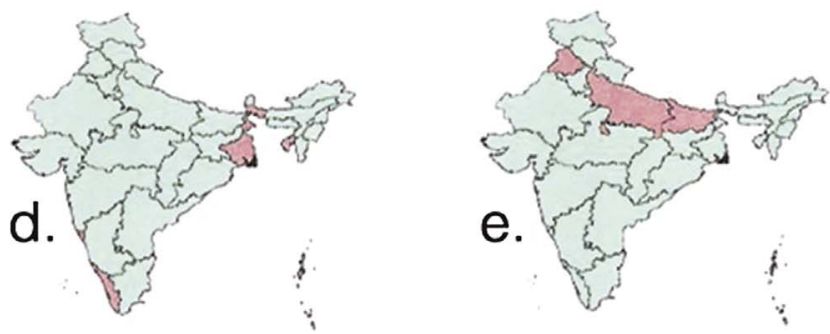

Low
a. rice
b. wheat
c. sugarcane
d. fruits \& vegetables
e. corn

in India conducted by the Department of Agriculture and Co-operation. ${ }^{6}$ The gross cropped area (in hectares) used by each state was then abstracted for specific crops in 2000-2001: wheat, corn, rice, and sugarcane. The dataset did not separate individual fruits and vegetables, but rather combined them into one broad category. The fruits-and-vegetables category included the following: mango, apple, banana, grapes, guava, citrus, pineapple, cauliflower, potato, onion, tomato, cabbage, ginger, and turmeric. The gross cropped area (in hectares) used by each state within India was obtained for the broad category fruits-and-vegetables from the 1999-2000 census data. The gross cropped area in hectares was then converted to $\mathrm{km}^{2}$. Census data from the years 1999-2000 were selected to best reflect the CML diagnosis date from the GIPAP centers.

The CML patients' age at diagnosis, occupation, and state of residence were obtained from the GIPAP service program of Novartis run by the MAX Foundation. ${ }^{3}$ All diagnosis dates for CML patients were before 2009. The occupation category had data for the listed occupation of the patient's head of household (who may or may not have been the patient). This original occupation variable had approximately $25 \%$ missing data and had a wide range of occupations listed.

\subsection{Endpoints}

The primary analysis examined differences in mean age at CML diagnosis for patients residing in high production states versus low production states for the following crops: corn, wheat, rice, sugarcane, and fruits/vegetables. A secondary analysis examined differences in age at CML diagnosis in high production states versus low production states (for all crops examined) in patients with agriculture/fishing occupations versus all other occupations.

\subsection{Statistical methods}

To determine crop specific land use percentages, each state's total area (in $\mathrm{km}^{2}$ ) was used as the denominator, and each state's total gross cropped area per each of the five crops identified earlier was used as the numerator.

States within India were ranked according to land-use percentage based on each of the five chosen crops to assess cutoff points for categorizing states into high or low production. Using univariate analysis, the $90 \%$ quantile cutoff point determined high-percentage states. The $90 \%$ cutoff point was chosen to better assure that only high-yielding states were considered "high" to draw appropriate conclusions. Thus, the top $10 \%$ of states per each crop's land use was considered to be high and the rest were low (Fig. 1).

The mean, standard deviation (SD), and the median were found for CML age at diagnosis for the entirety of India. The distribution of the age of CML diagnosis followed a normal distribution, so the mean (as opposed to median) was then determined for each state within India.

The MAX Foundation dataset combined the occupations for 
agriculture and fishing into one variable labeled: agriculture/fishing. A dichotomous variable for agriculture/fishing was created. If a patient's occupation was agriculture/fishing they were placed in the "yes" category of this variable. If a patient's occupation was self-employed, business, education, transport, government service, hospitality, or manufacturing, they were placed in the "no" category of the agriculture/fishing variable. Listed occupations of "other," "student," and "retired" were not included in the occupation analysis in an attempt to better age-match the comparison group. The mean and SD of CML age at diagnosis were then found for each stratum ("yes" and "no") of this new occupation variable.

For each crop, linear regression analyses were performed along with least squares means (LS-means) to examine unadjusted means and associated p-values for CML ages at diagnosis among the different crop categories. In five separate linear regression analyses, age of CML diagnosis was the dependent variable and each individual crop categorical variable was the sole independent predictor. Next, multivariable adjusted regression analyses were performed to examine adjusted means and associated p-values from CML ages at diagnosis among the different crop categories. In these models, age of CML diagnosis was the dependent variable and all five crop categorical variables were included as independent predictors.

Multivariable adjusted regression was repeated, stratified by occupation categorized as agriculture/fishing to examine crop pattern associations for those working in the agriculture/fishing sector vs. patients working in the other specific sectors listed above.

Finally, a sensitivity analysis was performed. Unadjusted and adjusted survival analyses were performed using Cox regression to assess whether time until age of CML diagnosis varied by crop category. Unadjusted models were used with each crop category as the sole predictor. The adjusted model used all the crop categories as predictors. The adjusted Cox proportional hazards regression method was then repeated in a stratified analysis to assess the crop pattern hazard ratios for those working in the agriculture/fishing sector compared to those patients working in all other occupational sectors (was self-employed, business, education, transport, government service, hospitality, or manufacturing).

All statistical analyses were performed using SAS Version 9.3, SAS Institute, Cary, NC, for Windows.

\section{Results}

A total of 14,177 CML patients were included in the analysis. The mean CML age at diagnosis for all patients in the study was 38.1 years (SD, \pm 13.96 years).

Of the 14,177 participants across India, 3,242 (23.2\%) listed agriculture/fishing as the occupation of the head of household. The mean age at diagnosis for CML of patients in the study with agriculture/ fishing as the family occupation was $37.9( \pm 13.89)$ years. Of the 14,177 participants across India, 2,202 (15.5\%) had listed self-employed, business, education, transport, government service, hospitality, or manufacturing as the occupation of the head of household. The mean CML age at diagnosis for those participants combined was 37.9 ( \pm 13.09 ) years. Of the 3,242 participants that listed agriculture/ fishing as the occupation of the head of household, roughly $80 \%$ were employed in agriculture.

Table 1 displays results for unadjusted and adjusted regression analysis for all patients with all crops. The adjusted multivariable regression analysis revealed significant differences in mean CML age at diagnosis between the high and low production categories for the following two crops: corn and fruits-and-vegetables. Patients residing in high corn-percentage states had a mean CML age at diagnosis 1.37 years earlier than those patients residing in low corn-percentage states (p-value $=.0183$ ). Patients residing in high fruits-and-vegetables-percentage states had a mean CML age at diagnosis 2.17 years later than those patients residing in low fruits-and-vegetables-percentage states (p-value $<.0001$ ). Corn and fruits-and-vegetables were the only two crop categories that remained significant through both unadjusted and adjusted analysis.

Table 2 displays hazard ratios with confidence limits and associated p-values for all predictor crop categories used in the adjusted survival analysis model. Results from the adjusted survival analysis (with all crop categories as predictors) using Cox proportional hazards regression found significant differences in time until CML age at diagnosis between the high and low categories for the following two predictor crops: corn and fruits-and-vegetables. Patients residing in the high cornpercentage states had a hazard ratio of 1.11 (p-value $=.0126$ ) for CML when compared to those patients residing in low corn-percentage states. Patients residing in the high fruits-and-vegetables-percentage states had a hazard ratio of 0.854 (p-value $<.0001$ ) for CML when compared to those patients residing in low fruits-and-vegetables-percentage states.

Adjusted regression analysis results for mean CML age at diagnosis stratified by patient occupation are displayed in Table 3. For those patients with a listed occupation of agriculture/fishing, significant differences were found in the mean age of CML diagnosis between the high and low categories for rice and fruits-and-vegetables. Agriculture/ fishing patients residing in high rice-percentage states had a mean CML age at diagnosis 2.71 years earlier than those agriculture/fishing patients residing in low rice-percentage states (p-value $=.009$ ). Agriculture/fishing patients residing in high fruits-and-vegetables-percentage states had a mean CML age at diagnosis 4.72 years later than those agriculture/fishing patients residing in low fruits-and-vegetables-percentage states ( $\mathrm{p}$-value $<.0001$ ). For those patients with the other listed occupations, significant differences were found in mean CML age at diagnosis between the high and low categories only for sugarcane. Non-agriculture/fishing patients residing in high sugarcane-percentage states had a mean CML age at diagnosis 3.38 years later than nonagriculture/fishing patients residing in low sugarcane-percentage states (p-value $=.0313)$.

The adjusted Cox proportional hazards regression results stratified by the dichotomous occupation variable for agriculture/fishing are shown in Table 4. For agriculture/fishing patients, an elevated hazard ratio (HR) for an earlier age at diagnosis was found for patients residing in high rice-percentage states as compared to those residing in low ricepercentage states $(\mathrm{HR}=1.15$, p-value $=.069)$. Agriculture/fishing patients had a lower hazard ratio for patients residing in high fruitsand-vegetables-percentage states as compared to those residing in low fruits-and-vegetables-percentage states $(\mathrm{HR}=0.732, \quad \mathrm{p}$-value $<$ .0001). For non-agriculture/fishing patients, no crop category had significant results in the adjusted Cox proportional hazards regression.

\section{Discussion}

In the analysis of all patients within the study, participants residing in states with the highest percentage of land used for corn had an earlier mean CML age at diagnosis and elevated hazard ratios compared with those patients residing in states with the lowest percentage of land used for corn. Corn associations were not significant in either occupational category in the stratified analysis (i.e. when restricted to patients with the listed occupation agriculture/fishing). Thus, the association of high corn-percentage-states and age at diagnosis in the entire patient population would perhaps suggest a dietary or lifestyle association rather than an agricultural practice association.

Patients residing in states with the highest percentage of their land used for the broad category fruits-and-vegetables (mango, apple, banana, grapes, guava, citrus, pineapple, cauliflower, potato, onion, tomato, cabbage, ginger, and turmeric) had a later mean CML age at diagnosis and lower hazard ratio. This could suggest a dietary component is involved. Those in high fruits-and-vegetables-percentage states are likelier to have fruits and vegetables as part of their diet, and this diet could be a protective factor against earlier CML diagnosis. The only 
Table 1

Unadjusted and Adjusted Mean CML Age at Diagnosis among State Crop Categories at the 90\% Quantile Cutoff for High and Low Percentage.

\begin{tabular}{|c|c|c|c|c|c|c|}
\hline Crop & Unadjusted Mean (years) & Mean Difference ${ }^{\mathrm{b}}$ (95\% C.I.) & P-value ${ }^{c}$ & Adjusted Mean $^{\mathrm{a}}$ (years) & Mean Difference $^{\mathrm{b}}$ (95\% C.I.) & P-value ${ }^{c}$ \\
\hline \multicolumn{7}{|l|}{ Corn } \\
\hline $\operatorname{High}^{d}(n=2115)^{f}$ & 36.626 & -1.738 & $<.0001$ & 37.643 & -1.369 & .0183 \\
\hline Low $^{e}(\mathrm{n}=12062)$ & 38.364 & $(-2.38,-1.09)$ & & 39.012 & $(-2.51,-0.23)$ & \\
\hline \multicolumn{7}{|l|}{ Wheat } \\
\hline High $(n=2043)$ & 36.997 & -1.294 & .0001 & 38.168 & -0.318 & .6348 \\
\hline Low $(\mathrm{n}=12134)$ & 38.291 & $(-1.95,-0.64)$ & & 38.486 & $(-1.63,0.99)$ & \\
\hline \multicolumn{7}{|l|}{ Rice } \\
\hline High $(n=2102)$ & 38.379 & 0.323 & .3283 & 38.238 & -0.178 & .6862 \\
\hline Low $(\mathrm{n}=12075)$ & 38.056 & $(-0.32,0.97)$ & & 38.416 & $(-1.04,0.69)$ & \\
\hline \multicolumn{7}{|l|}{ Sugarcane } \\
\hline High $(n=3129)$ & 37.498 & -0.778 & .0059 & 38.592 & 0.528 & .2393 \\
\hline Low $(n=11048)$ & 38.276 & $(-1.33,-0.22)$ & & 38.063 & $(-0.35,1.41)$ & \\
\hline \multicolumn{7}{|l|}{ Fruits \& Vegetables } \\
\hline High $(n=2303)$ & 39.989 & 2.251 & $<.0001$ & 39.411 & 2.168 & $<.0001$ \\
\hline Low $(\mathrm{n}=11874)$ & 37.739 & $(1.63,2.87)$ & & 37.243 & $(1.40,2.94)$ & \\
\hline
\end{tabular}

Adjusted Regression Model: $\mathrm{R}^{2}=0.0048, \mathrm{P}$-value $=<.0001$.

${ }^{\text {a }}$ Multivariable model adjusted for the possibility of overlapping crop categories.

${ }^{b}$ Difference in mean of age at diagnosis between high and low percentage states using a least squares means procedure for comparison with $95 \%$ confidence intervals for the mean difference.

${ }^{\mathrm{c}}$ P-value for the mean difference comparison.

${ }^{\mathrm{d}}$ High refers to all states within India that are above the $90 \%$ quantile for percentage of land used on specific crop.

${ }^{\mathrm{e}}$ Low refers to all states within India that are below the $90 \%$ quantile for percentage of land used on specific crop.

$\mathrm{f}$ " $\mathrm{n}$ " Refers to the number of participants within each category.

Table 2

Hazard Ratios for Patients in High-Percentage Crop Categories; Unadjusted and Adjusted Results Using the 90\% Quantile Cutoff Point ${ }^{\mathrm{b}}$.

\begin{tabular}{|c|c|c|c|c|c|c|}
\hline Crop Planted & Unadjusted Hazard Ratio & 95\% C.I. & $\mathrm{P}$-value & Adjusted $^{\mathrm{a}}$ Hazard Ratio & 95\% C.I. & P-value \\
\hline Corn High vs. Low & 1.144 & $(1.092,1.198)$ & $<.0001$ & 1.111 & $(1.023,1.207)$ & .0126 \\
\hline Wheat High vs. Low & 1.106 & $(1.056,1.159)$ & $<.0001$ & 1.010 & $(0.919,1.110)$ & .8321 \\
\hline Rice High vs. Low & 0.984 & $(0.940,1.031)$ & .4989 & 1.015 & $(0.955,1.079)$ & .6350 \\
\hline Sugarcane High vs. Low & 1.069 & $(1.027,1.112)$ & .0010 & 0.976 & $(0.916,1.040)$ & .4520 \\
\hline Fruits \& Vegetables High vs. Low & 0.847 & $(0.810,0.886)$ & $<.0001$ & 0.854 & $(0.809,0.901)$ & $<.0001$ \\
\hline
\end{tabular}

Adjusted Model, Global Null: Chi-square $=74.38$, P-value $<.0001$.

${ }^{a}$ Model adjusted for the possibility of overlapping crop categories.

${ }^{\mathrm{b}}$ Reference for hazard ratios is the low-percentage category for each crop-percentage category.

time the fruits-and-vegetables regions were not significantly associated with mean CML age at diagnosis was in the stratified analysis for those working in the following comparative occupational grouping: self-employed, business, education, transport, government service, hospitality, and manufacturing. One possible explanation as to the lack of protective effect in this group is that people with these occupations tend to be of a higher socio-economic status than people in the agriculture/fishing sector and would thus have diets that were less influenced by the region of residence.

The analysis stratified by patient occupation offered interesting results. Patients employed in agriculture/fishing in high rice-percentage states had a significantly earlier mean CML age at diagnosis. The high rice-percentage states were not significantly associated with age at diagnosis for the entire patient population or those with non-agriculture/ fishing occupations. This could suggest harmful occupational chemical associations with the agriculture practices among paddy growers in India. Three recent studies in Puducherry, West Bengal, and Andra Pradesh, India, assessed knowledge of the potential dangers and safe use of pesticides and found that awareness and knowledge among farmers were inadequate. ${ }^{7-9}$ Furthermore, communities where knowledge was adequate had incomplete implementation of safety measures. Since certain leukemia cell types have been previously linked to specific agricultural practices (i.e. farming of specific crops) and Indian CML age at diagnosis is relatively low, our study findings should be used a jumping off point for further, more in-depth analysis. ${ }^{2,10-12}$

The limitations of this study come with its ecological and exploratory nature. Additionally, the agriculture/fishing occupation category did not distinguish between the two occupations. Therefore, while the agriculture/fishing occupation is made up of roughly $80 \%$ agriculture, individual inference still should be made with caution. The variable for occupation had missing data $(25.7 \%)$. Large shifts in patterns in land use statistics in the years before or after 1999-2001 in India could also affect the interpretation of the study results. Finally, little is known about the quality and completeness of the agricultural land use data and the potential for incomplete reporting should be taken into account. Additionally, if a state is categorized as "high" for a specific crop in this study, it does not necessarily indicate that said crop is the most planted crop in that state.

This is the first study to utilize agricultural data within India to look for associations with CML. There were 5,444 patients in the multivariate regression analysis affording strong statistical power, and the data on CML patients were reliably collected. India is a potential highexposure setting for pesticide, herbicide, and insecticide use, and chemical intensive agricultural crop production needs additional scrutiny pertaining to potential occupational and environmental health effects.

It must be noted that our observations are based upon the knowledge available from questionnaire from the GPAP program - the overall occupational background of the majority of patients under study in specific geographic area. Specific occupation and exposure assessments through retrospective interview is not in the scope of this epidemiologic research. In future CML-focused studies, population-based registries and hospital records will help discern the etiologic linkage between 
Table 3

Adjusted Regression Analysis Results Stratified by Patient Occupation ${ }^{\text {a }}$ for $90 \%$ Quantile Cutoff Analysis.

\begin{tabular}{|c|c|c|c|c|c|c|}
\hline Crop & $\begin{array}{l}\text { Mean CML age at diagnosis } \\
\text { (years) }\end{array}$ & Mean Difference ${ }^{\mathrm{b}}$ (95\% C.I.) & P-value ${ }^{c}$ & $\begin{array}{l}\text { Mean CML age at diagnosis } \\
\text { (years) }\end{array}$ & Mean Difference $^{\text {b }}$ (95\% C.I.) & P-value ${ }^{c}$ \\
\hline & \multicolumn{3}{|c|}{ Agriculture/Fishing } & \multicolumn{3}{|c|}{ Non-Agriculture/Fishing ${ }^{f}$} \\
\hline \multicolumn{7}{|l|}{ Corn } \\
\hline High $^{d}$ & 39.697 & 1.588 & .1846 & 36.975 & -2.145 & .1320 \\
\hline Low $^{\mathrm{e}}$ & 38.108 & $(-0.76,3.95)$ & & 39.120 & $(-4.94,0.64)$ & \\
\hline \multicolumn{7}{|l|}{ Wheat } \\
\hline High & 38.555 & -0.694 & .6355 & 36.744 & -2.607 & .1887 \\
\hline Low & 39.250 & $(-3.57,2.18)$ & & 39.351 & $(-6.49,1.28)$ & \\
\hline \multicolumn{7}{|l|}{ Rice } \\
\hline High & 37.547 & -2.710 & .0090 & 38.202 & 0.308 & .7881 \\
\hline Low & 40.257 & $(-4.74,-0.68)$ & & 37.894 & $(-1.93,2.55)$ & \\
\hline \multicolumn{7}{|c|}{ Sugarcane } \\
\hline High & 38.510 & -0.784 & .4574 & 39.735 & 3.375 & .0313 \\
\hline Low & 39.295 & $(-2.85,1.28)$ & & 36.360 & $(0.30,6.45)$ & \\
\hline \multicolumn{7}{|c|}{ Fruits \& Vegetables } \\
\hline High & 41.262 & 4.719 & $<.0001$ & 38.784 & 1.473 & .2011 \\
\hline Low & 36.543 & $(2.81,6.63)$ & & 37.311 & $(-0.79,3.73)$ & \\
\hline
\end{tabular}

${ }^{\text {a }}$ Multivariable model adjusted for the possibility of overlapping crop categories.

b Difference in mean of age at diagnosis between high and low states with $95 \%$ confidence intervals for the mean difference.

${ }^{\mathrm{c}}$ P-value for the mean difference comparison.

${ }^{\mathrm{d}}$ High refers to all states within India that are above the $90 \%$ quartile for percentage of land used on specific crop.

e Lowrefers to all states within India that are below the $90 \%$ quartile for percentage of land used on specific crop.

${ }^{\mathrm{f}}$ Self-employed, business, education, transport, government service, hospitality, or manufacturing.

Table 4

Hazard Ratios for Patients in High-Percentage Crop Categories, Stratified by Patient Occupation $^{\mathrm{b}}$ for the $90 \%$ Quantile Cutoff Analysis.

\begin{tabular}{|c|c|c|c|c|c|c|}
\hline \multirow[b]{2}{*}{ Crop Planted } & \multicolumn{3}{|c|}{ Agriculture/Fishing } & \multicolumn{3}{|c|}{ Non-Agriculture/Fishing ${ }^{\mathrm{c}}$} \\
\hline & $\begin{array}{l}\text { Hazard } \\
\text { Ratio }^{\mathrm{a}}\end{array}$ & $95 \%$ C.I. & P-value & $\begin{array}{l}\text { Hazard } \\
\text { Ratio }^{a}\end{array}$ & 95\% C.I. & P-value \\
\hline $\begin{array}{l}\text { Corn High vs. } \\
\text { Low }\end{array}$ & 0.913 & $\begin{array}{l}(0.771, \\
1.082)\end{array}$ & 0.2929 & 1.189 & $\begin{array}{l}(0.954, \\
1.482)\end{array}$ & 0.1242 \\
\hline $\begin{array}{l}\text { Wheat High vs. } \\
\text { Low }\end{array}$ & 1.013 & $\begin{array}{l}(0.827, \\
1.242)\end{array}$ & 0.9005 & 1.114 & $\begin{array}{l}(0.823, \\
1.506)\end{array}$ & 0.4850 \\
\hline $\begin{array}{l}\text { Rice High vs. } \\
\text { Low }\end{array}$ & 1.146 & $\begin{array}{l}(0.989 \\
1.328)\end{array}$ & 0.0690 & 1.009 & $\begin{array}{l}(0.853, \\
1.195)\end{array}$ & 0.9139 \\
\hline $\begin{array}{c}\text { Sugarcane } \\
\text { High vs. } \\
\text { Low }\end{array}$ & 1.083 & $\begin{array}{l}(0.933 \\
1.258)\end{array}$ & 0.2942 & 0.845 & $\begin{array}{l}(0.668 \\
1.070)\end{array}$ & 0.1619 \\
\hline $\begin{array}{l}\text { Fruits \& } \\
\quad \text { Vegetables } \\
\text { High vs. } \\
\text { Low }\end{array}$ & 0.732 & $\begin{array}{l}(0.641 \\
0.836)\end{array}$ & $<0.0001$ & 0.937 & $\begin{array}{l}(0.791) \\
1.110)\end{array}$ & 0.4506 \\
\hline
\end{tabular}

${ }^{\text {a }}$ Model adjusted for the possibility of overlapping crop categories.

${ }^{b}$ Reference for hazard ratios is the low category for each crop-percentage category.

c Self-employed, business, education, transport, government service, hospitality, or manufacturing.

agricultural exposure and CML. When these in-depth registries are up and running, our study can serve as a baseline for research direction.

\section{Conflict of interest}

None.

\section{Acknowledgments}

This research was conducted at and funded by the George Washington University School of Public Health and Health Services. Figures were created by Harrison Schillinger, Industrial Designer.

\section{References}

1. Mendizabal A, Younes N, Levine PH. Geographic and income variations in age at diagnosis and incidence of chronic myeloid leukemia. Int J Hematol. 2016;103(1):70-78.

2. Mendizabal AM, Garcia-Gonzalez P, Levine PH. Regional variations in age at diagnosis and overall survival among patients with chronic myeloid leukemia from low and middle income countries. Cancer Epidemiol. 2013;37(3):247-254.

3. Lassaret S, Jootar S. Ongoing challenges of a global international patient assistance program. Ann Oncol. 2005(Supplement 8).

4. American Cancer Society. Cancer facts \& figs. 2014. Atlanta, GA: American Cancer Society; 2014.

5. Levine PH, Zhou C, Ajmera K, et al. Demographic factors for young age at diagnosis of chronic myeloid leukemia in India. Clin Epidemiol Glob Health. 2016;4(4):188-192.

6. Department of Agriculture and Co-operation (1999-2001), Agriculture census database. http://agcensus.nic.in.

7. Banerjee I, Tripathi SK, Sinha Roy A, Sengupta P. Pesticide use pattern among farmers in a rural district of West Bengal, India. J Nat Sci Biol Med. 2014;5(2):313-316.

8. Lavanya Kumari P, Giridhar Reddy K. Knowledge and practices of safety use of pesticides among farm workers. J Agric Vet Sci. 2013;6(2):1-8.

9. Mohanty MK, Behera BK, Jena SK, et al. Knowledge attitude and practice of pesticide use among agricultural workers in Puducherry, South India. J Forensic Legal Med. 2013;20(8):1028-1031.

10. Blair A, White DW. Death certificate study of leukemia among farmers from Wisconsin. J Natl Cancer Inst. 1981;66(6):1027-1030.

11. Blair A, Thomas TL. Leukemia among Nebraska farmers: a death certificate study. Am J Epidemiol. 1979;110(3):264-273.

12. Blair A, White DW. Leukemia cell types and agricultural practices in Nebraska. Arch Health: Int J. 1985;40(4):211-214. 